NBER WORKING PAPER SERIES

\title{
RESOLVING MACROECONOMIC UNCERTAINTY IN STOCK AND BOND MARKETS
}

\author{
Alessandro Beber \\ Michael W. Brandt \\ Working Paper 12270 \\ http://www.nber.org/papers/w12270
}

\author{
NATIONAL BUREAU OF ECONOMIC RESEARCH \\ 1050 Massachusetts Avenue \\ Cambridge, MA 02138 \\ May 2006
}

We thank Mikhail Chernov, Michael Fleming, Michael Johannes, Krishna Ramaswamy, Pascal St-Amour, Suresh Sundaresan, and seminar participants at Baruch College, Carnegie Mellon University, Columbia University, the Federal Reserve Bank of New York, the University of Illinois, the University of North Carolina, the University of Lausanne, and the University of Wisconsin for comments. We also thank Goldman Sachs and, in particular, Bill Cassano for providing the economic derivatives auction results and for explaining institutional details. George Gatopoulos and Sergei Sontchik provided able research assistance. This research was partially funded by the National Center of Competence in Research managed by the Swiss National Science Foundation. The views expressed herein are those of the author(s) and do not necessarily reflect the views of the National Bureau of Economic Research.

(C2006 by Alessandro Beber and Michael W. Brandt. All rights reserved. Short sections of text, not to exceed two paragraphs, may be quoted without explicit permission provided that full credit, including () notice, is given to the source. 
Resolving Macroeconomic Uncertainty in Stock and Bond Markets

Alessandro Beber and Michael W. Brandt

NBER Working Paper No. 12270

May 2006

JEL No. G1

\begin{abstract}
We establish an empirical link between the ex-ante uncertainty about macroeconomic fundamentals and the ex-post resolution of this uncertainty in financial markets. We measure macroeconomic uncertainty using prices of economic derivatives and relate this measure to changes in implied volatilities of stock and bond options when the economic data is released. We also examine the relationship between our measure of macroeconomic uncertainty and trading activity in stock and bond option markets before and after the announcements. Higher macroeconomic uncertainty is associated with greater reduction in implied volatilities. Higher macroeconomic uncertainty is also associated with increased volume in option markets after the release, consistent with market participants waiting to trade until economic uncertainty is resolved, and with decreased open interest in option markets after the release, consistent with market participants using financial options to hedge macroeconomic uncertainty. The empirical relationships are strongest for long-term bonds and weakest for non-cyclical stocks.
\end{abstract}

Michael W. Brandt

Fuqua School of Business

Duke University

Box 90120

One Towerview Drive

Durham, NC 27708

and NBER

mbrandt@duke.edu 


\section{Introduction}

How important is uncertainty about macroeconomic fundamentals for financial markets? The literature has tried to answer this question indirectly by measuring the response of asset prices, including those of derivatives, to macroeconomic announcements. ${ }^{1}$ Evidence that new information about the economy matters for financial markets implies that uncertainty in these markets should be associated with uncertainty about the state of the economy. Consistent with this reasoning, Ederington and Lee (1996) and Beber and Brandt (2006) document that the uncertainty implicit in options written on U.S. Treasury bond futures drops substantially after the release of macroeconomic news. This observation suggests that when financial markets learn about the state of the economy, some uncertainty in financial markets is resolved. However, despite this indicative evidence, we still do not know precisely how and to what extent the ex-post resolution of uncertainty in financial markets is related to the ex-ante uncertainty of market participants about the state of the economy.

Uncertainty about the state of the economy is unobserved and therefore difficult to quantify. Previous studies have used measures of cross-sectional disagreement, such as the standard deviation of forecasts across economists, to proxy for uncertainty (e.g., Andersen, Bollerslev, Diebold, and Vega (2003)), but such disagreement measures are generally weakly correlated with measures of true uncertainty (see Zarnowitz and Lambros (1987)). We establish a more direct link between the ex-ante uncertainty of macroeconomic fundamentals and the ex-post resolution of uncertainty in financial markets. We measure macroeconomic uncertainty using prices of economic derivatives traded in a new auction-based market launched in 2002 jointly by Goldman Sachs and Deutsche Bank. These economic derivatives represent explicit bets on news about macroeconomic fundamentals and their option-implied standard deviations therefore provide a direct measure of the ex-ante uncertainty of market participants about the news release.

Although the economic derivatives market is relatively young, it is already closely watched by market participants and the media before scheduled macroeconomic announcements as a barometer of market views. For example, Bloomberg News reported the following before a recent announcement of U.S. payroll statistics: ${ }^{2}$

\footnotetext{
${ }^{1}$ Several recent papers have investigated the response of bond, stock, and currency markets to scheduled macroeconomic announcements (e.g., Balduzzi, Elton, and Green (2001), Flannery and Protopapadakis (2002), and Andersen, Bollerslev, Diebold and Vega (2005)). The results reveal a significant impact of economic announcements on returns, their volatility, and market liquidity.

${ }^{2}$ Source: "Dollar advances on speculation job growth may exceed forecasts," Bloomberg News, May 7, 2004. Other headlines for this announcement include "... economic derivatives offered by Deutsche Bank and Goldman Sachs showed markets betting on Friday for February jobs growth of around 137,000. Markets had been going for about 145,000 on Thursday." ("Dollar firm while U.S. jobs data looms," Reuters News, March
} 
... U.S. employers probably added 170,000 jobs last month, according to the median estimate of 75 economists surveyed by Bloomberg News. The Labor Department releases the figures at 8:30 a.m. in Washington. Traders expect 186,200 jobs new in April, an auction of economic derivatives showed. The derivatives, created by Deutsche Bank AG and Goldman Sachs Group Inc and marketed through ICAP Plc, were auctioned yesterday and today.

Besides this high degree of visibility, economic derivatives are likely to provide an accurate measure of ex-ante uncertainty about the state of the economy for at least two other reasons. ${ }^{3}$ First, the market for economic derivatives is dominated by sophisticated investors (predominantly hedge funds and proprietary trading desks). Second, auctions take place only one or two days prior to the announcement, leaving little room for market views to change before the subsequent news release.

Our paper makes at least two contributions to the literature. First, we establish explicitly the link between ex-ante uncertainty about economic fundamentals and the expost resolution of this uncertainty in financial markets. Based on our results, we can predict, for instance, how a temporary or structural change in the uncertainty about economic fundamentals will affect the volatility of bonds, stock indices, and individual stocks. There are several reasons for the uncertainty about economic fundamentals to change, including the economy transitioning into a new phase of the business cycle (a temporary change) or the Government changing its statistical reporting protocol (a structural change). Second, we examine how the ex-ante uncertainty about economic fundamentals is related to trading activity in financial markets, as measured by open interest and volume, before and after the announcement. Trading activity tells us how market participants deal with (i.e., hedge or speculate) uncertainty about the state of the economy.

The design of our analysis is straightforward. We first confirm that stock and bond markets react to macroeconomic announcements in our sample period. We then extract measures of macroeconomic uncertainty from the observed prices of economic derivatives. Finally, we relate these measures of macroeconomic uncertainty to changes in implied volatility of stock and bond options when the economic data is released as well as to the changes in transacted volume and open interest in stock and bond option markets.

5, 2004) and "... economists expected February payrolls to rise 130,000, according to a survey conducted by CBS MarketWatch. In the economic derivatives market run by Goldman Sachs, Deutsche Bank and ICAP were looking for a gain of about 140,000 new positions." (CBS/AP, March 5, 2004).

${ }^{3}$ In a concurrent paper, Gürkaynak and Wolfers (2005) show that expectations derived from economic derivatives are somewhat more accurate than survey-based forecasts. 
We find that higher ex-ante uncertainty about macroeconomic fundamentals is associated with greater reduction in the implied volatilities of stock and bond options when the economic data is released. The results are more pronounced for bonds than for stocks. Specifically, we observe that the degree of uncertainty about the Non-Farm Payroll (NFP) report, for example, explains more than 40 percent of the drop in the volatility of Treasury bond futures and more than 20 percent of the drop in the volatility of Eurodollar futures. This resolution in bond market uncertainty appears to be permanent. We also observe an association, although weaker, between macroeconomic uncertainty and the implied volatilities of stock index options. Finally, we document that within the stock index, cyclical stocks are substantially more exposed to macroeconomic uncertainty than non-cyclical stocks.

Concerning the link between macroeconomic uncertainty and trading behavior, we find evidence that the degree of uncertainty affects significantly the trading strategies employed by market participants for both options written on Treasury bond futures and on cyclical stocks. In particular, higher macroeconomic uncertainty is associated with a greater increase in transacted volume after the news release. This observation is consistent with market participants waiting to trade until after the resolution of economic uncertainty and suggests that the "calm before the storm" effect is calmer the stronger the storm is expected to be. We also find a negative relation between macroeconomic uncertainty and the reduction of open interest after the news release. This result is consistent with market participants closing out hedging positions and with the degree of hedging activity depending on the degree of macroeconomic uncertainty to be hedged.

Besides contributing to the growing literature on the response of financial markets to macroeconomic news (e.g., Ederington and Lee (1996), Beber and Brandt (2006), and the references in footnote 1), our paper relates to the research examining the economic sources of return volatility. David and Veronesi (2002) show that an uncertainty measure obtained from a model of real earnings growth is related to the implied volatilities of equity options. Buraschi and Jiltsov (2005) find that a proxy for the differences in beliefs forecasts the implied volatility of index options and is related to index options volume. Dubinsky and Johannes (2005) study the evolution of uncertainty around earnings announcements using the implied volatilities of individual equity options. We add to this literature by employing an economic uncertainty measure that is based on prices of economic derivatives and is thus market-based, high-frequency, and intrinsically related to the macro economy. These features of our uncertainty measure allow us to uncover a strong relation between the uncertainty of economic fundamentals and financial markets volatility. We also demonstrate how the link between macroeconomic fundamentals and financial markets depends on the type of assets, with long-term bonds at one extreme and non-cyclical stocks at the other. 
The paper proceeds as follows. In Section 2 we describe the economic derivatives and financial options data. Section 3 explains our methodology for estimating the uncertainty implicit in economic derivatives and how we relate this measure to the implied volatilities in financial markets and to the trading strategies of options market participants. We present our empirical results in Section 4. Section 5 concludes with a summary of our findings.

\section{Data}

\subsection{Economic derivatives}

Goldman Sachs and Deutsche Bank launched the market for derivative securities on scheduled macroeconomic announcements, covering initially non-farm payrolls (NFP), the Institute of Supply Management (ISM) manufacturing report, and U.S. retail sales ex-autos (RS) in October 2002. ${ }^{4}$ The liquidity of this market was enhanced shortly thereafter through an agreement with ICap (the largest interdealer broker for over-the-counter derivatives) to distribute the securities to the inter-dealer market. ${ }^{5}$ Economic derivatives are priced parimutuelly in a Universal Dutch auction in which as many orders as possible are filled at the same clearing price. ${ }^{6}$ This auction format is designed to maximize liquidity.

We collect data on auctions of economic derivatives completed between October 2002 and June 2005 from Goldman Sachs. Our sample consists of 161 auctions covering 32 releases of non-farm payroll, 28 releases of the Institute of Supply Management manufacturing report, 25 releases of retail sales ex-autos, and 51 releases of initial jobless claims.

Economic derivatives are structured as calls, puts, and digital options. These securities can be traded by themselves or in combinations such as spreads, straddles, strangles, and risk reversals. The strike prices are set to reflect the range of possible outcomes. The payoffs of the call (put) options are capped at the highest (lowest) available strike price. The underlying is the initial release of a given macroeconomic statistic on the scheduled announcement date. Revisions of the data that typically follow the initial release do not matter for the payoffs of economic derivatives. The client base for economic derivatives is primarily hedge funds,

\footnotetext{
${ }^{4}$ Contracts on other releases were introduced later. Specifically, contracts on the Eurozone harmonized index of consumer prices (HICP) were introduced in May 2003, contracts on initial job claims started trading in February 2004, contracts on the U.S. gross domestic product started trading in January 2005, and contracts on the U.S. international trade balance were introduced in February 2005.

${ }^{5}$ The Chicago Mercantile Exchange (CME) and Goldman Sachs recently announced a partnership to further enhance the liquidity of economic derivatives through integrated clearing and marketing agreements.

${ }^{6}$ All trades at a given strike are executed at the same price, as it is common in Dutch auctions. However, in the case of economic derivatives, it is possible to enter limit orders. The equilibrium price is determined by an auction-clearing algorithm that maximizes total trades.
} 
proprietary trading desks, and inflation swap traders.

There are typically two auctions for each announcement. At the beginning of the sample, the first auction was held three days before the release and the second auction was held one day before the release. After experimenting for a short period with only one auction the day before the release, there are now again two auctions. The first auction is held in the afternoon of the day before the release and the second auction is held in the early morning of the day of the release. Anecdotal evidence suggests that the participation in the first auction is mainly from U.S. customers, whereas the second auction gets slightly more than half U.K. and European participation. We do not have figures on transacted volume. However, we gather through informal conversations with Goldman Sachs that digital options are about three quarters of the trades yet less than half of the transacted volume. Vanilla options are generally preferred by hedgers and are therefore transacted in greater size and volume. Figure 1 provides a snapshot of our data for one auction.

\section{$2.2 \quad$ Fixed income options}

We collect daily at-the-money implied volatilities from Datastream for options on the 30-year Treasury bond futures traded at the CBOT, options on the 10-year Treasury note futures traded also at the CBOT, and options on the Eurodollar futures traded at the CME, for the sample period of the economic derivatives data. These options are American-style and Datastream thus computes their implied volatilities using a binomial model. We also obtain prices of options on the 5-year Treasury note futures directly from the CBOT, where they are traded, and compute implied volatilities using the same approach as Datastream. ${ }^{7}$ We also collect daily data on transacted volume and open interest for each option contract written on the 30-year Treasury bond futures, 10-year Treasury note futures, 5-year Treasury note futures, and Eurodollar futures from the CBOT and CME.

For each underlying asset, we obtain two series of at-the-money implied volatilities. The first series uses option settlement prices from the nearest expiry month, interpolating between the implied volatilities of options with strike prices immediately above and below the price of the underlying. This series switches to the next available month on the first day of the expiry month. We also obtain a series of at-the-money implied volatility for a constant time to maturity of 30 days, computed by interpolating the implied volatilities of options maturing immediately before and after 30 days. ${ }^{8}$ We construct both implied volatility series using only

\footnotetext{
${ }^{7}$ Datastream does not cover options on the 5-year Treasury note futures before the end of 2003.

${ }^{8}$ Datastream provides this series of at-the-money implied volatility also for maturities of 90 days and 180 days. Since the macroeconomic announcements that we investigate are released monthly, it is reasonable to
} 
call options, using only put options, or using both. In general, we present empirical results obtained from implied volatilities using both call and put options, since this measure is more robust to measurement errors (see Hentschel (2003)). However, our results are robust to these various ways of constructing the implied volatility series.

\subsection{Equity options}

We also collect daily data on the CBOE volatility index (VIX) for our sample period. VIX is a measure of expected stock market volatility over the next 30 days computed from market prices of Standard and Poors (S\&P) 500 index options traded at the CBOE. The VIX calculation is based on a weighted average of out-of-the-money put and call prices and does not rely on a specific option pricing model. ${ }^{9}$ In addition, we obtain daily data on S\&P 500 index options as well as on individual equity options from OptionMetrics. The data consists of midpoint quotes at the close, implied volatilities (computed by OptionMetrics using either the Black-Scholes formula for the European style index options or a binomial tree model for the American style individual equity options), and standard sensitivity measures. Due to the delay in the database update, this part of our data only goes through December 2004.

In contrast to index options, options markets for many individual firms are very illiquid. In order to assure a minimum level of liquidity and hence data integrity, we focus exclusively on individual equity options for firms that are part of the S\&P 100 index, since an explicit requirement for membership in this index is to have a liquid options market. ${ }^{10}$ We then sort stocks into industries and further into groups of industries that we anticipate to be cyclical or non-cyclical. Specifically, we base our industry classification on the results of Boudoukh, Richardson, and Whitelaw (1994), who sort industries by their correlation between industry level output growth and aggregate output growth. We label the five industries with the highest output growth beta as cyclical and the five industries with the lowest output growth beta as non-cyclical. ${ }^{11}$ This sorting procedure results in a sample of individual equity options on 22 cyclical firms and on 14 non-cyclical firms.

expect the strongest impact at a 30-day horizon. We therefore focus on 30 days maturities in our empirical analysis but also verified that our results are robust to using longer time to maturity options.

${ }^{9}$ The CBOE website provides further details on the VIX construction methodology.

${ }^{10}$ See the S\&P 100 index fact sheet. Driessen, Maenhout, and Vilkov (2005) use the same selection criteria.

${ }^{11}$ We use the output growth betas from Table 1 of Boudoukh, Richardson, and Whitelaw (1994). The cyclical industries are primary metals, transportation equipment, rubber and plastics, metal products, and electrical machinery. The non-cyclical industries are food and beverage, tobacco, utilities, printing and publishing, and petroleum products. 


\section{Methodology}

\subsection{Pricing economic derivatives}

We infer the implied mean and standard deviation of the macroeconomic news release from the prices of both digital and vanilla options on the announcement. We use options with all strike prices from the auction closest to the announcement. To compute the option-implied moments, we make two simplifying assumptions. We assume that the underlying economic release is normally distributed around the mean forecast and that markets are complete. The normality assumption is empirical quite reasonable, but the completeness assumption is more controversial. While the release of a macroeconomic statistic is clearly a nontraded underlying, there are many traded assets with returns that are highly correlated with economic news (e.g., bonds). Furthermore, we need the assumption of market completeness only to obtain an estimate of the uncertainty about the release implicit in economic derivatives, without implying that this is a precise or even unique measure of the variance of the risk-neutral distribution. Unless errors in our inferences are systematically correlated with asset prices, which they should not be especially when markets are incomplete, we expect market incompleteness to only bias our analysis against finding significant results.

The price of a vanilla call option on the economic statistic $F$ with expiration date $T$ (the release date) and with strike price $K$ is:

$$
C_{T, K}=\mathrm{E}_{t}\left[M_{t, T}\left(F_{T}-K\right)^{+}\right]
$$

where $M_{T}$ denotes a stochastic discount factor and $x^{+} \equiv \max (0, x)$. Assuming markets are complete, we express, without loss of generality, the stochastic discount factor as a function of the underlying, $M_{T}=M\left(F_{T}\right)$. The price of the call option is then:

$$
\begin{aligned}
C_{T, K} & =\int_{0}^{\infty} M\left(F_{T}\right)\left(F_{T}-K\right)^{+} p_{t}\left(F_{T}\right) d F_{T} \\
& =\mathrm{e}^{-r(T-t)} \int_{0}^{\infty}\left(F_{T}-K\right)^{+} q_{t}\left(F_{T}\right) d F_{T},
\end{aligned}
$$

where $p_{t}\left(F_{T}\right)$ denotes the conditional distribution of the economic release, $q_{t}\left(F_{T}\right)$ denotes the corresponding risk-neutral distribution defined by the transformation:

$$
q_{t}\left(F_{T}\right) \equiv \mathrm{e}^{r(T-t)} M\left(F_{T}\right) p_{t}\left(F_{T}\right)
$$

and $r$ is the continuously compounded $(T-t)$-period interest rate. Since the auction and 
the release generally take place on the same day, we consider the effect of discounting as negligible and drop the discount factor from equation (3). Finally, we eliminate the max operator by limiting the range of integration:

$$
C_{T, K}=\int_{K}^{\infty}\left(F_{T}-K\right) q_{t}\left(F_{T}\right) d F_{T}
$$

We assume that the risk-neutral distribution $q_{t}(F)$ of the economic release is conditionally Gaussian with mean $\mu$ and standard deviation $\sigma$. Under this assumption, the solution to equation (4) is similar to the Black-Scholes formula:

$$
C_{K, T}=\left[E\left(F_{T} \mid F_{T} \geq K\right)-K\right] \Phi\left(-K^{*}\right)
$$

with $K^{*}=(K-\mu) / \sigma$ and

$$
E\left(F_{T} \mid F_{T} \geq K\right)=\mu+\frac{\phi\left(K^{*}\right)}{1-\Phi\left(K^{*}\right)} \sigma
$$

Equation (6) represents the expected value of the economic release conditional on the option being exercised. $\phi(x)$ and $\Phi(x)$ denote standard normal probability density and cumulative distribution functions evaluated at $x$, respectively. ${ }^{12}$ Since the payoff of the traded call is capped at the highest available strike price (cap), we obtain the price of the capped call by adding a short position in a call at the highest strike price:

$$
C_{K, T}^{c a p}=C_{K, T}-C_{K=c a p, T}
$$

The price of a vanilla put options under the normality assumption is given by:

$$
P_{K, T}=\left[K-E\left(F_{T} \mid F_{T} \leq K\right)\right] \Phi\left(K^{*}\right),
$$

where

$$
E\left(F_{T} \mid F_{T} \leq K\right)=\mu-\frac{\phi\left(K^{*}\right)}{\Phi\left(K^{*}\right)} \sigma
$$

The payoff of the traded put is capped at the lowest strike price (floor) and can be obtained by adding a short positions in a put option with the lowest strike price:

$$
P_{K, T}^{c a p}=P_{K, T}-P_{K=f l o o r, T}
$$

\footnotetext{
${ }^{12}$ The expected value of the normally distributed economic release conditional on exercise corresponds to the expected value of a truncated normal distribution, where the truncation point is given by the strike price. See Johnson and Kotz (1970) for the formula of the expected value of a truncated normal random variable.
} 
The normality assumption also leads to relatively simple expressions for the prices of digital options. Under risk-neutral pricing, the price of a digital call option is given by:

$$
D C_{T, K}=\mathrm{e}^{r(T-t)} \int_{K}^{\infty} q\left(F_{t}, F_{T}\right) d F_{t, T}
$$

Under normality and dropping again the discount factor, this expression simplifies to:

$$
D C_{K, T}=\Phi\left(-K^{*}\right)
$$

Similarly, the price for a digital put option is given by:

$$
D P_{K, T}=\Phi\left(K^{*}\right)
$$

The ultimate goal of this section is to arrive at a way to estimate the parameters of the Gaussian risk-neutral distribution, $\mu$ and $\sigma$, for each macroeconomic news release using options with different strike prices. Consider for a given announcement at date $T$ a cross-section of $N$ prices of vanilla and digital call and put options which differ only in their strike prices $K_{i},\left\{C_{T, K_{1}}^{c a p}, \ldots, C_{T, K_{N}}^{c a p}\right\},\left\{P_{T, K_{1}}^{c a p}, \ldots, P_{T, K_{N}}^{c a p}\right\},\left\{D C_{T, K_{1}}, \ldots, D C_{T, K_{N}}\right\}$, and $\left\{D P_{T, K_{1}}, \ldots, D P_{T, K_{N}}\right\} .{ }^{13}$ We estimate the parameters of the underlying risk neutral distribution by numerically solving the non-linear least-squares (NLLS) problem:

$$
\begin{aligned}
\min _{\mu, \sigma} & \sum_{i=1}^{N}\left[\frac{C_{T, K_{i}}^{c a p}-C_{T, K_{i}}^{c a p}(\mu, \sigma)}{C_{T, K_{i}}^{c a p}}\right]^{2}+\sum_{i=1}^{N}\left[\frac{P_{T, K_{i}}^{c a p}-P_{T, K_{i}}^{c a p}(\mu, \sigma)}{P_{T, K_{i}}^{c a p}}\right]^{2} \\
& +\sum_{i=1}^{N}\left[\frac{D C_{T, K_{i}}-D C_{T, K_{i}}(\mu, \sigma)}{D C_{T, K_{i}}}\right]^{2}+\sum_{i=1}^{N}\left[\frac{D P_{T, K_{i}}-D P_{T, K_{i}}(\mu, \sigma)}{D P_{T, K_{i}}}\right]^{2}
\end{aligned}
$$

where the first option price in the squared brackets represents the data and the second term is the corresponding theoretical price from equations (7), (10), (12), and (13).

\subsection{Economic and financial markets uncertainty}

For each macroeconomic announcement with a pre-announcement auction, we obtain an estimate of the uncertainty $\sigma_{t}$ implicit in the prices of the economic derivatives using the procedure described above. We then test whether this measure of ex-ante uncertainty about

\footnotetext{
${ }^{13}$ The prices of vanilla options can be approximated by combinations of digital options if there exists a continuum of strike prices. The prices of call and put options with the same strike price is also linked through put-call parity. However, since strike prices are discretely spaced, we do not have information on the liquidity of each contract, and the underlying is in principle a non-traded asset, we assume that each option contract contains independent information. We thus use all the available option prices in our estimation.
} 
economic fundamentals has predictive ability for the ex-post resolution of uncertainty in financial markets. More specifically, we estimate the following regression:

$$
\left(\frac{I V_{t}-I V_{t-1}}{I V_{t-1}}\right)=\alpha+\beta \sigma_{t}+e_{t}
$$

where $I V_{t-1}$ is the implied volatility of a given financial security (e.g., bond, equity index, or individual equity) the day prior to the news release and $I V_{t}$ is the implied volatility the day of the news release (after the announcement). We also estimate equation (15) using $I V_{t+1}$ in place of $I V_{t}$ to understand whether the resolution of uncertainty is transitory and whether the process of uncertainty resolution is instantaneous or takes some time.

The resolution of uncertainty in the equity market can be overshadowed by the leverage effect - the empirical observation that a large negative return tends to be associated more with an increase in volatility than an equally large positive return. If, for some reason, stock prices drop on the announcement day, implied volatility increases due to the leverage effect and any resolution of uncertainty related to the macroeconomic release is harder to detect. When we estimate regression (15) for the equity index or individual equities, we therefore explicitly control for the leverage effect using the following regression specification:

$$
\left(\frac{I V_{t}-I V_{t-1}}{I V_{t-1}}\right)=\alpha+\beta \sigma_{t}+\gamma \operatorname{Ret}_{t, t-1}+e_{t},
$$

where $\operatorname{Ret}_{t, t-1}$ represents the return of the underlying asset on the announcement day.

Similarly, we investigate the trading behavior of market participants in the financial option markets by estimating the following two regressions:

$$
\begin{aligned}
& \frac{\left(\text { Volu }_{t}-\text { Volu }_{t-1}\right)}{\text { Volu }_{t-1}}=\alpha+\beta \sigma_{t}+e_{t}, \\
& \frac{\left(\text { Oint }_{t}-\text { Oint }_{t-1}\right)}{\text { Oint }_{t-1}}=\alpha+\beta \sigma_{t}+e_{t},
\end{aligned}
$$

where Volu $_{t}$ and Oint $_{t}$ are respectively the traded volume and open interest on the day of the announcement for the financial options contracts with closest quarterly maturity date. ${ }^{14}$

\footnotetext{
${ }^{14}$ The empirical results are very similar if we consider trading volume and open interest of the options closest to maturity, regardless of whether it is a quarterly maturity date or not, or if we consider volume and open interest of all options with less than 60 days to maturity.
} 


\section{Empirical results}

\subsection{Do financial markets react to macroeconomic news?}

A precondition for macroeconomic uncertainty to be related to volatility in financial markets is that the new information released in the announcement moves asset prices. If financial markets do not react to macroeconomic news, there is no reason to expect that uncertainty about economic fundamentals is reflected in bond and stock market volatility. We therefore begin our empirical analysis by investigating whether bond and stock prices respond at the daily frequency to macroeconomic news during our sample period. ${ }^{15}$

To gauge the extent to which an announcement contains new information, we construct the following standardized measure of surprise:

$$
S_{t}=\frac{A_{t}-\mu_{t}}{\sigma}
$$

where $A_{t}$ is the value of the economic statistic released at time $t, \mu_{t}$ denotes the corresponding market forecast implied by the economic derivatives prices and obtained by solving the problem in equation (14), and $\sigma$ is the (unconditional) empirical standard deviation of the innovations $A_{t}-\mu_{t}$. Standardizing the surprise by the empirical standard deviation helps in the interpretation of the results. We then estimate the following regression:

$$
\operatorname{Ret}_{t, t-1}=\alpha+\beta S_{t}+e_{t}
$$

where $\operatorname{Ret}_{t, t-1}$ represents the percentage daily return on either the 30-year Treasury bond futures (US), the 10-year Treasury note futures (TY), the 5-year Treasury-note futures (FV), the Eurodollar futures (ED), the S\&P 500 index, the portfolio of cyclical stocks, or the portfolio of non-cyclical stocks.

Table 1 presents the regression results for the case of non-farm payrolls (NFP), which is by far the most influential macroeconomic announcement during our sample period. ${ }^{16}$ Panel A shows that a positive surprise in NFP is associated with strongly negative bond returns.

\footnotetext{
${ }^{15}$ While there is strong evidence in the literature that bond markets respond intra-daily to macroeconomic news (e.g., Fleming and Remolona, 1999a) and some evidence that stock markets also respond intra-daily to the same news (e.g., Flannery and Protopapadakis, 2002), it is important for the empirical design of our paper to test whether this is true at the daily frequency and during our sample period.

${ }^{16}$ During our sample period, NFP is always released concurrently with the civilian unemployment rate (CUR) in the employment report (ER). To ensure that the results in Table 1 are not driven by the CUR release, we also include as regressor the standardized surprise of the CUR release, using the median forecast provided by Money Market Services as proxy for market expectations. The results for the NFP release do not change in this expanded regression specification.
} 
In all cases, the $R^{2}$ indicates that more than 45 percent of the variance of announcement day bond returns is explained by the surprises in NFP. More specifically, a one-standard deviation positive surprise in NFP is associated with a negative $82,62,44$, and three basis point daily return for the US, TY, FV, and ED futures, respectively. If we transform these bond returns into bond yield changes using the modified duration of the underlying, we naturally obtain the opposite ranking, i.e., the effect of NFP surprises on yields is greater for shorter maturity and smaller for longer maturity bonds (results not tabulated).

Surprises in NFP have far less explanatory power for stock returns. Specifically, the announcement day return on the $\mathrm{S} \& \mathrm{P} 500$ index is not significantly related to the surprises in NFP. Any effect of the macroeconomic news on aggregate cashflows and discount rates appears to be either offsetting (i.e., discount rates and expected cashflows changing in the same direction) or swamped by other news about individual firm cashflows. Consistent with this later explanation, we observe a weakly significant, at the 10 percent level, relationship between the return on cyclical stocks and NFP surprises, explaining almost 10 percent of the variation in announcement day returns of cyclical stocks. A one standard deviation positive surprise in NFP is associated with a 46 basis points higher average daily return on the portfolio of cyclical stocks. Additional analysis, not reported in the table, reveals that if we estimate the regression (20) separately for each cyclical stock, we obtain positive slope coefficients for 20 of the 22 stocks, with eight being significant at least at the 10 percent level. For two stocks the slope coefficient is negative but insignificant.

\subsection{Implied macroeconomic uncertainty}

We compute the macroeconomic uncertainty implied by the economic derivatives for all NFP announcements in our sample using data from the auctions directly preceding the news releases. We focus again on NFP because it is the most influential macroeconomic announcement, and we consider only the second auction because it reflects the most up-todate information before the announcement. It turns out, however, that the informational contents of the auction held in the afternoon of the day before the announcement and of the auction held in the morning of the day of the announcement are very similar. Specifically, the implied forecasts $\mu_{t}$ of the two auctions have a correlation of 0.99 and the implied volatilities $\sigma_{t}$ have a correlation of 0.86 .

Figure 2 plots our measure of macroeconomic uncertainty (dotted line), the VIX (light solid line), and the 30-day implied volatility of Treasury bond futures (dark solid line). We observe a pronounced downward trend in the implied return volatilities during our sample period. Both stock and bond returns became less volatile. However, this downward trend 
is not shared by the uncertainty about NFP releases. If anything, economic fundamentals became more uncertain. It is clear from this figure that economic uncertainty and financial markets volatility are far from perfectly correlated in levels. We hence turn to a more detailed analysis relating macroeconomic uncertainty to changes in financial markets volatility.

\subsection{Do financial markets reflect macroeconomic uncertainty?}

\subsubsection{Bonds}

As a first step in analyzing the resolution of macroeconomic uncertainty in bond markets, we compute the unconditional average implied volatility of at-the-money call and put options on the day before the NFP release and at the close of the announcement day. The average at-the-money implied volatility the day before the announcement is 11.26 percent for options written on the 30-year Treasury bond futures (US), 7.72 percent for options on the 10-year Treasury note futures (TY), 5.39 percent for options on the 5-year Treasury note futures (FV), and 30.59 percent for options on Eurodollar futures (ED), respectively. ${ }^{17}$ The average at-the-money implied volatility after the announcement is 10.18 percent for options on US, 6.87 percent for options on TY, 4.74 percent for options on FV, and 27.83 percent for options on ED, respectively. This represents a percentage decrease in implied volatility of 9.59 percent for options on US, 11.01 percent for options on TY, 12.01 percent for options on FV, and 9.02 percent for options on ED. We conclude from this evidence that bond market volatility drops unconditionally on macroeconomic announcement days.

Table 2 shows the results of regressing the percentage change in the implied volatility of options written on US, TY, FV, or ED, on the uncertainty about the NFP announcement implied by the economic derivatives. ${ }^{18}$ We observe that for the longer maturities (US, $\mathrm{TY}$, and FV), more than 40 percent of the across-announcement day variation in the volatility drop is explained by the ex-ante uncertainty about the NFP release. The higher the ex-ante uncertainty about NFP, the greater is the drop in implied volatility following the announcement. This result is apparent in both the implied volatility of the closest maturity options and the interpolated volatility with a 30 -day horizon. ${ }^{19}$ The relationship between macroeconomic uncertainty and changes in bond market volatility is not only highly significant statistically but also important economically. For example, a high degree of

\footnotetext{
${ }^{17}$ The volatility of Eurodollar futures is conventionally quoted on the basis of the implied discount rate, given by 100 minus the prevailing futures price.

${ }^{18} \mathrm{We}$ also regress the percentage change in squared implied volatilities on $\sigma_{t}^{2}$, i.e. the risk-neutral variance of the distribution of the economic release. The results are very similar, both in terms of statistical significance and economic magnitude.

${ }^{19}$ We also obtain significant results, albeit weaker, when we measure volatility at a 90 -day horizon.
} 
uncertainty about NFP equal to the average uncertainty in our sample plus two standard deviations predicts about a 37 percent drop in the 30-days implied volatility of US or TY options. This drop is obviously very large compared to the unconditional drop in implied volatility of only 10 percent on announcement days.

To see if the resolution of uncertainty is transitory, we also test whether the effects on implied volatility are still present at the close of the day following the announcement. ${ }^{20} \mathrm{We}$ observe that the effects of macroeconomic uncertainty on bond markets uncertainty persist, both in terms of magnitude and statistical significance of the coefficients. The explanatory power of macroeconomic uncertainty for the longer horizon drop in volatility is somewhat lower, but still more than one third in general.

We also try to understand whether there is a systematic role for good versus bad news about the economy in resolving the uncertainty in bond markets. For this, we add as a regressor the standardized surprise in the NFP release. The results (not tabulated) show that the new information embedded in the surprise does not have a significant impact on the change in bond implied volatilities. This also holds when we interact the standardized surprise in the release with our measure of macroeconomic uncertainty.

\subsubsection{Aggregate stock index}

Table 3 shows the results for the S\&P 500 index. In Panel A, we use changes in the average implied volatilities of S\&P 500 index options interpolated to have a constant time to maturity of 30 days. Panel B is for changes in the average implied volatilities of the closest to maturity options and next closest to maturity options, respectively. All but one of the coefficients relating changes in the implied index volatilities to our measure of macroeconomic uncertainty are negative, in line with the results in Table 2 . In contrast to those bond market results, however, none of the coefficients for the stock index are statistically significant. This result is consistent with the observation from Table 1 that the stock index does not react strongly to macroeconomic news. The resolution of economic uncertainty therefore also has only little effect on the index volatility.

The coefficients on the index return are all negative and, as expected, highly significant. Recall from the discussion surrounding equation (16) that we add the index return to explicitly take into account the well-documented leverage effect. Judging by the $R^{2}$ of the regressions, the leverage effect explains a vast majority of the changes in index volatility.

\footnotetext{
${ }^{20}$ Since the non-farm payrolls are generally released on Friday, we actually test if the relation between implied volatility and macroeconomic uncertainty is still present after the weekend.
} 


\subsubsection{Cyclical and non-cyclical stocks}

Given the considerably weaker results for the S\&P 500 index, relative to the results for longand short-term bonds, we next consider a basket of options written on cyclical stocks. The goal is to examine how the effect of macroeconomic uncertainty differs for stocks that we know, from the regressions in Table 1, react more strongly to macroeconomic announcements. Table 4 shows the results for cyclical stocks using again either the percentage change in interpolated 30-day implied volatilities (Panel A) or the percentage change in raw implied volatilities (Panel B). The regression specification is identical to that for the stock index. However, we apply an additional data filter in this case. We include in the analysis only options that are traded on both the pre-announcement day and on the announcement day. This is done to avoid any bias induced, for example, by options on volatile stocks being traded on only one of the two days causing a spurious difference between the average implied volatilities before and after the announcements.

Table 4 shows that the implied volatility of cyclical stocks is indeed related to the uncertainty about macroeconomic fundamentals. Higher ex-ante uncertainty about NFP is associated with a greater drop in implied volatility when the uncertainty is resolved. This relation is statistically significant at the 10 percent level in all cases. The coefficient is greatest in magnitude for the short maturity raw implied volatilities in Panel B, consistent with the monthly timing of NFP announcements. Finally, we note that the drop in implied volatility appears to persist, given that the coefficients for the day after the release are similar in magnitude and statistical significance.

For comparison, we also repeat the analysis for non-cyclical stocks. The results, which are not tabulated to conserve space, show that the volatility of non-cyclical stocks is unrelated to the uncertainty about macroeconomic fundamentals. The coefficients on the ex-ante uncertainty about NFP are never statistically significant, their magnitudes are small compared to the results for cyclical stocks, and the sign is even positive in a number of cases. These results confirm that non-cyclical stocks are relatively immune to changes in macroeconomic conditions, not only because contemporaneously their prices do not respond to announcements (see Table 1) but also because ex-ante their implied volatilities do not reflect the degree of uncertainty about fundamentals.

\subsection{How do markets deal with macroeconomic uncertainty?}

Our results thus far document a strong link between the ex-ante uncertainty about NFP releases and financial markets volatility. Clearly financial markets, and especially bond markets, are concerned about changes in macroeconomic conditions and the uncertainty 
associated with scheduled macroeconomic announcements. Given this empirical fact, it is reasonable to expect market participants to trade in a way that also reflects the degree of uncertainty about macroeconomic fundamentals. Specifically, we expect a greater degree of hedging or speculating before macroeconomic releases that are more uncertain, since the benefits of hedging or the gains from speculating increase with uncertainty. In this section, we explore this hypothesis further by examining the relationship between the ex-ante uncertainty about NFP releases and changes in trading volume and open interest in bond and equity options on announcement days.

\subsubsection{Bonds}

Table 5 presents the results of regressing the change in the trading volume for the closest quarterly maturity bond options on the ex-ante uncertainty about NFP releases. We observe that across the different option contracts a higher degree of macroeconomic uncertainty is associated with a greater increase in trading volume after the resolution of the uncertainty. We obtain the strongest statistical significance and explanatory power for the options written on the five-year Treasury note futures. This observation is consistent with the evidence in the literature that price discovery is most pronounced for intermediate maturities (e.g., Fleming and Remolona, 1999b; Brandt and Kavajecz, 2004). The results are qualitatively the same when we analyze separately the trading volume of call and put options (see panels B and C). Although there is not a clear pattern is these disaggregated results, it appears that call option trading volume is most important for the long and short bond maturities, whereas put option trading volume plays a larger role for intermediate bond maturities. Finally, the relation between macroeconomic uncertainty and trading volume is not only statistically significant but also economically important. For example, a high degree of uncertainty about NFP equal to one standard deviation above the mean uncertainty predicts a 35 percent increase in traded volume of FV call and put options, more than three times the unconditional increase in trading volume of 11 percent on announcement days.

These results on trading volume are consistent with market participants using options to hedge against or speculate on the forthcoming NFP release. The greater the uncertainty about NFP, the greater are the benefits from hedging or gains from speculating. If a hedge or speculative position is entered into gradually over the days preceding the announcement and then unwound once the news is release, we would observe an increase in trading volume after the announcement. The magnitude of this increase in trading volume would depend on the size of the hedge or speculative position, which, in turn, is related on the degree of macroeconomic uncertainty. An alternative explanation is that market participants wait to 
trade for reasons unrelated to the announcement until the uncertainty about NFP is resolved. The higher the uncertainty, the greater are the incentives to wait.

To gain further insight into which of these two explanations is more plausible, we examine next the relationship between ex-ante macroeconomic uncertainty and the change in open interest on the announcement day. The hedging/speculating explanation predicts a decrease in open interest while the waiting to trade explanation predicts an increase. In both cases, the rise or drop in open interest should in magnitude be related to the degree of macroeconomic uncertainty. Table 6 presents the aggregated results for all near-term options in Panel A and the disaggregated results for near-term call and put options in panels B and C, respectively. Higher macroeconomic uncertainty is consistently associated with a greater decrease in open interest on the announcement day, which is consistent only with the hedging/speculating explanation. The coefficients are more significant for options written on the ten-year Treasury note futures when we consider the open interest of all options or call options, and more significant for options written on the five-year Treasury note and the Eurodollar futures when we consider the open interest of put options. Note, however, that the relation between macroeconomic uncertainty and changes in open interest is less important economically, compared to the results for the changes in trading volume. For example, a high degree of uncertainty about NFP equal to one standard deviation above the mean uncertainty predicts a 0.6 percent decrease in the open interest of put options written on the five-year Treasury note futures, compared to an unconditional increase of 1.3 percent on announcement days. This lower level of economic importance may be because the two explanations largely offset each other. As hedgers and speculators unwind their positions, other traders open new ones for reasons unrelated to the announcement, leaving open interest largely unchanged.

Finally, we examine the patterns in option trading volume for several days preceding the announcement. The aim of this analysis is to shed further light on whether the difference in trading volume from before to after the announcement is due to volume being unusually low before the announcement, a "calm before the storm" effect, or unusually high after the announcement, from the unwinding of hedge and speculative positions. The results are not tabulated to conserve space, but we discuss here the findings for options written on the five-year Treasury note futures. We focus on the five-year maturity because it features the strongest response of trading volume to macroeconomic uncertainty. The results for the other maturities are qualitatively similar. Unconditionally, we find that there is a significant drop in option trading volume one and two days before the announcement, relative to three and four days before the announcement as well as relative to one and two days after the announcement. Conditionally, the drop in trading volume during this two-day period before the announcement increases with the degree of macroeconomic uncertainty. This evidence is 
consistent with a calm before the storm effect and with this calm being calmer the stronger the storm is expected to be. In conjunction with our open interest evidence above, these results also confirm our earlier conjecture that market participants enter into hedge or speculative position several days prior to the announcement.

\subsubsection{Aggregate stock index}

Turning next to the equity market, we first conduct the same analysis for trading volume and open interest of S\&P 500 index options. Given the lack of an empirical relationship between macroeconomic uncertainty and changes in implied volatility of index options, we do not expect to observe a relationship between macroeconomic uncertainty and trading activity. Nevertheless, the stock index results as serve natural benchmark for the more interesting findings involving cyclical stock options presented below.

Table 7 shows the results for option trading volume. In all cases, there is a positive relationship between macroeconomic uncertainty and changes in trading volume of call and put options, just as we observe for the bond market. However, none of the coefficients is statistically significant, and the explanatory power of the regressions is very modest. Table 8 presents the corresponding results for changes in open interest. In this table, the effect of macroeconomic uncertainty is less clear, with coefficients taking different signs for different maturities and for call versus put options. Again, none of the coefficients is statistically significant, and the explanatory power of the regressions is very modest. We conclude that, as expected, there is no evidence of a relationship between macroeconomic uncertainty and trading activity in stock index options.

\subsubsection{Cyclical and non-cyclical stocks}

Since cyclical stocks react more strongly to macroeconomic news (see Table 1) and their implied volatilities reflect the uncertainty about upcoming announcements (see Table 4), it seems logical to expect that trading activity in cyclical stock options is also more responsive to the degree of macroeconomic uncertainty. We therefore examine next the changes in trading volume and open interest of options written on cyclical stocks surrounding NFP announcements. Table 9 documents the relation between our measure of macroeconomic uncertainty and changes in trading volume of all cyclical options (in Panel A) and of cyclical call and put options separately (in panels B and C). In all cases, greater macroeconomic uncertainty is associated with a larger increase in option trading volume immediately following the announcement, mirroring our results for bonds in Section 4.4.1. In aggregate as well as for calls alone, this relation is strongest, both in economic magnitude and statistical 
significance, for medium maturity options with an average of 46 days to maturity. For puts, in contrast, the results are strongest for shorter maturities of 15 days on average. Table 10 complements this analysis with corresponding results for changes in open interest. In all cases, greater macroeconomic uncertainty is associated with a larger drop in open interest following the announcement. In aggregate and for calls, this effect is significant only for medium maturities. For puts, the coefficients on macroeconomic uncertainty are significant, at least marginally at the ten-percent level, even for short maturities.

These results are in principle again consistent with two different trading motives. Market participants could be using cyclical stock options to either hedge against or speculate on the economic release. Both activities predict that the announcement is followed by higher volume and a drop of open interest as hedge or speculative positions are unwound. Furthermore, in both cases the benefits from hedging or the potential gains from speculating increase with the degree of uncertainty about the announcement, leading to indistinguishable regression estimates. However, economic intuition makes hedging the more likely explanation of our results for cyclical stocks. This is because it seems far more likely that cyclical stock options are used to hedge against the effect of macroeconomic news on the cyclical stocks that underly these options, than that cyclical stock options are used to speculate broadly on announcements. After all, it is considerably cheaper to trade fixed income futures options than individual equity options, and the relation between bond returns and macroeconomic news is more than five times less noisy than that between cyclical stock returns and macroeconomic news (see Table 1). We conclude that, while our results for cyclical stocks are consistent with speculative trading, this explanation seems economically implausible.

For completeness, we repeat this analysis one last time for non-cyclical stocks. The results, which are not tabulated to conserve space, confirm our earlier findings that noncyclical stocks are even less related to macroeconomic announcements than the aggregate market index. Neither changes in option trading volume nor changes in open interest are significantly related to the uncertainty about NFP announcements. Furthermore, the regression coefficients on our measure of macroeconomic uncertainty take on different signs for different maturities and option types.

\section{Conclusion}

We established an empirical link between the ex-ante uncertainty about macroeconomic fundamentals and the ex-post resolution of this uncertainty in financial markets. We measured macroeconomic uncertainty using prices of economic derivatives and related 
this measure to changes in implied volatilities of stock and bond options when the economic data is released. Across the different assets we considered, we found that higher macroeconomic uncertainty is associated with greater reduction in implied volatilities. For bonds, the relationship between macroeconomic uncertainty and changes in implied volatility is statistically and economically highly significant. Our uncertainty measure captures more than 50 percent of the variation in the drop of implied volatility across announcement days. Furthermore, a high degree of uncertainty equal to one standard deviation above the average uncertainty in our sample predicts more than a one-third drop in the implied volatility of medium- to long-term bond options, compared to an unconditional drop in implied volatility of about 10 percent on announcement days. The results are considerably weaker for the aggregate stock index. We showed, by further decomposing the aggregate stock index into cyclical and non-cyclical stocks, that these weaker results are largely due to non-cyclical stocks not responding to macroeconomic news. Cyclical stocks exhibit qualitatively the same significant relation between macroeconomic uncertainty and changes in implied volatility as bonds, though quantitatively the results for cyclical stocks are still weaker.

We also examined the relationship between our measure of macroeconomic uncertainty and trading activity in stock and bond option markets surrounding the announcements. Higher macroeconomic uncertainty is associated with greater volume as well as larger drops in open interest of both bond and cyclical stock options following the announcements. These results are consistent with market participants using the option markets to either hedge against or speculate on the macroeconomic releases. We argued, however, that, at least in the case of cyclical stock options, the hedging explanation is economically more plausible. 


\section{References}

Andersen, Torben G., Tim Bollerslev, Francis X. Diebold, and Clara Vega, 2003, Micro effects of macro announcements: Real-time price discovery in foreign exchange, American Economic Review 93, 38-62.

Andersen, Torben G., Tim Bollerslev, Francis X. Diebold, and Clara Vega, 2005, Real-time price discovery in stock, bond and foreign exchange markets, Working Paper, Northwestern University, Duke University, University of Pennsylvania and University of Rochester.

Balduzzi, Pierluigi, EdwJ. Elton, and T. Clifton Green, 2001, Economic news and bond prices: Evidence from the U.S. Treasury market, Journal of Financial and Quantitative Analysis 36, 523-543.

Beber, Alessandro, and Michael, W. Brandt, 2006, The effect of macroeconomic news on beliefs and preferences: Evidence from the options market, Journal of Monetary Economics, forthcoming.

Buraschi, Andrea, and Alexei, Jiltsov, 2005, Model uncertainty and option markets with heterogeneous agents, Journal of Finance, forthcoming.

Boudoukh, Jacob, Matthew Richardson, and Robert Whitelaw, 1994, Industry returns and the Fisher effect, Journal of Finance 49, 1595-1615.

Brandt, Michael and Kenneth Kavajecz, 2004, Price discovery in the U.S. Treasury market: The impact of orderflow and liquidity on the yield curve, Journal of Finance 59, 26232654 .

David, Alexander, and Pietro Veronesi, 2002, Option prices with uncertain fundamentals: Theory and evidence on the dynamics of implied volatilities, Working Paper, University of Chicago.

Driessen, Joost, Pascal, Maenhout, and Grigory, Vilkov, 2005, Option-implied correlations and the price of correlation risk, working paper, INSEAD.

Dubinsky, Andrew and Michael Johannes, 2005, Earnings announcements and equity options, working paper, Columbia University.

Ederington, Louis H., and Jae H. Lee, 1996, The creation and resolution of market uncertainty: The impact of information releases on implied volatility, Journal of Financial and Quantitative Analysis 31, 513-539.

Flannery, Mark J., and Aris A., Protopapadakis, 2002, Macroeconomic factors do influence aggregate stock returns, Review of Financial Studies 15, 751-782.

Fleming, Michael J., and Eli M. Remolona, 1999a, Price formation and liquidity in the U.S. Treasury market: The response to public information, Journal of Finance 54, 1901-1915.

Fleming, Michael J., and Eli M. Remolona, 1999b, The term structure of announcement effects , Federal Reserve Bank of New York Staff Reports. 
Gürkaynak, Refet S., and Justin Wolfers, 2005, Macroeconomic derivatives: An initial analysis of market-based macro forecasts, uncertainty, and risk, Working Paper, University of Pennsylvania.

Hentschel, Ludger, 2003, Errors in implied volatility estimation, Journal of Financial and Quantitative Analysis 38, 779-810.

Johnson, Norman L., and Samuel Kotz, 1970, Distributions in Statistics: Continuous Univariate Distributions, Vol. 1., Wiley, New York, NY.

Zarnowitz, Victor and Lambros, Louis A. Lambros, 1987, Consensus and uncertainty in economic prediction, Journal of Political Economy 95, 591-621. 


\section{Table 1: Macroeconomic news and financial markets returns}

This table shows the results of estimating the following regression:

$$
\operatorname{Ret}_{t, t-1}=\alpha+\beta S_{n f p, t}+e_{n f p, t},
$$

where Ret $_{t, t-1}$ represents, in Panel A ,the daily percentage return on the 30-year Treasury bond futures (US), the 10-year Treasury note futures (TY), the 5-year Treasury note futures (FV), or the Eurodollar futures (ED). In Panel B, Ret $t_{t, t-1}$ represents the daily percentage returns on the S\&P 500 index, the return on a portfolio of cyclical stocks, or the return on a portfolio of noncyclical stocks. $S_{n f p, t}$ represents the standardized difference between the actual NFP release and the implied market forecast, as defined in equation (19).

Panel A: Bond market

\begin{tabular}{lllll}
\hline & US & TY & FV & ED \\
\hline constant & -0.00134 & -0.00124 & -0.00074 & 0.00010 \\
std surprise & $-0.00817^{* * *}$ & $-0.00618^{* * *}$ & $-0.00444^{* * *}$ & $-0.00033^{* * *}$ \\
$R^{2}$ & 0.4666 & 0.5159 & 0.5306 & 0.5073 \\
observations & 32 & 32 & 32 & 32 \\
\hline
\end{tabular}

Panel B: Stock market

\begin{tabular}{llll}
\hline & S\&P 500 & Cyclical & Non-cyclical \\
\hline constant & -0.00028 & 0.00076 & -0.00046 \\
std surprise & 0.001249 & $0.00463^{*}$ & -0.00025 \\
$R^{2}$ & 0.0177 & 0.0924 & 0.0005 \\
observations & 32 & 32 & 32 \\
\hline
\end{tabular}

$* * *, * *$, and $*$ denote statistical significance at the one, five, and 10 percent levels, respectively. 


\section{Table 2: Resolution of bond market uncertainty}

This table shows the results of estimating the following regression:

$$
\left(I V_{t}-I V_{t-1}\right) / I V_{t-1}=\alpha+\beta \sigma_{t}+e_{t},
$$

where $I V_{t}$ is the implied volatility on the day of the release, obtained either from options with the closest maturity (column (1)), or interpolated at the 30 days horizon (column (2)). We also estimate the same regression substituting $I V_{t}$ with $I V_{t+1}$ (column (3) and (4)). Panel A, B, C, and $\mathrm{D}$ show the results for options on the 30-year Treasury bond futures (US), on the 10-year Treasury note futures (TY), on the 5-year Treasury note futures (FV), and on the Eurodollar futures (ED), respectively.

Panel A: US

\begin{tabular}{|c|c|c|c|c|}
\hline & $\begin{array}{l}(1) \\
\text { release day }\end{array}$ & $\begin{array}{l}(2) \\
\text { release day }\end{array}$ & $\begin{array}{l}(3) \\
\text { day after }\end{array}$ & $\begin{array}{l}\text { (4) } \\
\text { day after }\end{array}$ \\
\hline option's time to maturity & closest & 30 & closest & 30 \\
\hline constant & $0.15853^{* *}$ & $0.17990^{* * *}$ & $0.20451^{* * *}$ & $0.15632^{* *}$ \\
\hline economic $\sigma$ & $-0.00270^{* * *}$ & $-0.00272^{* * *}$ & $-0.00297^{* * *}$ & $-0.00227^{* * *}$ \\
\hline$R^{2}$ & 0.3754 & 0.4807 & 0.3494 & 0.2975 \\
\hline observations & 32 & 32 & 32 & 32 \\
\hline \multicolumn{5}{|c|}{ Panel B: TY } \\
\hline & (1) & $(2)$ & $(3)$ & (4) \\
\hline & release day & release day & day after & day after \\
\hline option's time to maturity & closest & 30 & closest & 30 \\
\hline constant & $0.17581^{* *}$ & $0.17093^{* * *}$ & $0.20946^{* *}$ & $0.18405^{* *}$ \\
\hline economic $\sigma$ & $-0.00302^{* * *}$ & $-0.00273^{* * *}$ & $-0.00320^{* * *}$ & $-0.00274^{* * *}$ \\
\hline$R^{2}$ & 0.3315 & 0.4174 & 0.3330 & 0.3373 \\
\hline observations & 32 & 32 & 32 & 32 \\
\hline
\end{tabular}


Panel C: FV

\begin{tabular}{|c|c|c|c|c|}
\hline & $\begin{array}{l}(1) \\
\text { release day }\end{array}$ & $\begin{array}{l}(2) \\
\text { release day }\end{array}$ & $\begin{array}{l}(3) \\
\text { day after }\end{array}$ & $\begin{array}{l}(4) \\
\text { day after }\end{array}$ \\
\hline option's time to maturity & closest & 30 & closest & 30 \\
\hline constant & $0.23289^{* * *}$ & $0.21440^{* * *}$ & $0.27178^{* * *}$ & $0.23143^{* * *}$ \\
\hline economic $\sigma$ & $-0.00374^{* * *}$ & $-0.00326^{* * *}$ & $-0.00393^{* * *}$ & $-0.00328^{* * *}$ \\
\hline$R^{2}$ & 0.4660 & 0.4196 & 0.4399 & 0.3909 \\
\hline observations & 32 & 32 & 32 & 32 \\
\hline \multicolumn{5}{|c|}{ Panel D: ED } \\
\hline & (1) & $(2)$ & $(3)$ & $(4)$ \\
\hline & release day & y release day & $y$ day after & day after \\
\hline option's time to maturity & y closest & 30 & closest & 30 \\
\hline constant & 0.07344 & $0.23242^{* *}$ & 0.14677 & $0.27281^{*}$ \\
\hline economic $\sigma$ & -0.00174 & $-0.00346^{* * *}$ & $-0.00242^{*}$ & $-0.00349^{* *}$ \\
\hline$R^{2}$ & 0.0605 & 0.2022 & 0.0935 & 0.1602 \\
\hline observations & 32 & 32 & 32 & 32 \\
\hline
\end{tabular}

$* * *, * *$, and $*$ denote statistical significance at the one, five, and 10 percent levels, respectively. 


\section{Table 3: Resolution of aggregate stock market uncertainty}

This table shows the results of estimating the following regression:

$$
\left(I V_{t}-I V_{t-1}\right) / I V_{t-1}=\alpha+\beta \sigma_{t}+\gamma \operatorname{Ret}_{t, t-1}+e_{t},
$$

where $I V_{t}$ is the stock market implied volatility and $\operatorname{Ret}_{t, t-1}$ is the S\&P 500 index return on the day of the release. We also estimate the same regression substituting $I V_{t}$ with $I V_{t+1}$ and $R e t_{t, t-1}$ with $\operatorname{Ret}_{t+1, t-1}$. Panel A shows the results for the average implied volatility obtained from all options on the S\&P 500 Index interpolated at a 30-day time to maturity. Panel B shows the results for the average implied volatility of options traded on both the pre-announcement and the announcement day for the traded maturities.

Panel A: S\&P 500 standardized options

\begin{tabular}{lcl}
\hline & release day & day after \\
\hline constant & 0.00615 & 0.04777 \\
S\&P 500 return & $-2.83677^{* * *}$ & $-3.46223^{* * *}$ \\
economic $\sigma$ & -0.00006 & -0.00042 \\
$R^{2}$ & 0.6552 & 0.6940 \\
observations & 27 & 27 \\
& &
\end{tabular}

Panel B: S\&P 500 raw options

\begin{tabular}{lllll}
\hline & release day & release day & day after & day after \\
\hline options' average time to maturity & 15.26 & 45.85 & 15.26 & 45.85 \\
average no. of options & 47.07 & 33.59 & 45.70 & 33.00 \\
constant & 0.01030 & -0.00895 & 0.14158 & $0.04918^{* *}$ \\
S\&P 500 return & $-1.10657^{*}$ & $-0.89356^{* *}$ & 0.21112 & $-0.66554^{*}$ \\
economic $\sigma$ & -0.00011 & 0.00012 & -0.00030 & -0.00033 \\
$R^{2}$ & 0.1233 & 0.1635 & 0.0051 & 0.1771 \\
observations & 27 & 27 & 27 & 27 \\
\hline
\end{tabular}

$* * *, * *$, and $*$ denote statistical significance at the one, five, and 10 percent levels, respectively. 


\section{Table 4: Resolution of cyclical stock uncertainty}

This table shows the results of estimating the following regression:

$$
\left(I V_{t}-I V_{t-1}\right) / I V_{t-1}=\alpha+\beta \sigma_{t}+\gamma \operatorname{Ret}_{t, t-1}+e_{t},
$$

where $I V_{t}$ is the implied volatility of a portfolio of cyclical stocks and $\operatorname{Ret}_{t, t-1}$ is the return of a portfolio of cyclical stocks on the day of the release. We also estimate the same regression substituting $I V_{t}$ with $I V_{t+1}$ and $\operatorname{Ret}_{t, t-1}$ with $\operatorname{Ret}_{t+1, t-1}$. Panel A shows the results for the average implied volatility obtained from all options on cyclical stocks interpolated at a 30-day time to maturity, traded on both the pre-announcement and the announcement day. Panel B shows the results for the average implied volatility of options traded on both the pre-announcement and the announcement day for the two traded maturities around the 30-day horizon.

Panel A: Standardized options on cyclical stocks

\begin{tabular}{lcc}
\hline & release day & day after \\
\hline constant & 0.01340 & $0.03539^{* *}$ \\
cyclical stocks return & $-1.03982^{* * *}$ & $-1.14837^{* * *}$ \\
economic $\sigma$ & $-0.00017^{*}$ & $-0.00017^{*}$ \\
$R^{2}$ & 0.7736 & 0.7955 \\
observations & 27 & 27 \\
\hline
\end{tabular}

Panel B: Raw options on cyclical stocks

\begin{tabular}{lllll}
\hline & release day & release day & day after & day after \\
\hline options' average time to maturity & 15.26 & 45.85 & 15.26 & 45.85 \\
average no. of options & 77.07 & 111.26 & 68.44 & 110.22 \\
& & & & \\
constant & 0.01929 & 0.01781 & $0.13544^{* * *}$ & $0.04574^{* * *}$ \\
cyclical stocks return & $-0.58717^{* *}$ & $-0.51209^{* * *}$ & -0.21530 & $-0.49318^{* * *}$ \\
economic $\sigma$ & $-0.00032^{*}$ & $-0.00020^{*}$ & $-0.00055^{*}$ & $-0.00023^{*}$ \\
$R^{2}$ & 0.2589 & 0.4306 & 0.0686 & 0.3763 \\
Observations & 27 & 27 & 27 & 27 \\
\hline
\end{tabular}

$* * *, * *$, and $*$ denote statistical significance at the one, five, and 10 percent levels, respectively. 


\section{Table 5: Bond market options volume}

This table shows the results of estimating the following regression:

$$
\left(\text { Volu }_{t}-\text { Volu }_{t-1}\right) / \text { Volu }_{t-1}=\alpha+\beta \sigma_{t}+e_{t},
$$

where $\mathrm{Volu}_{t}$ is the trading volume for option contracts with the closest quarterly maturity traded on the release day $t$. Column (1) shows the results for options on the 30-year Treasury futures (US), column (2) for options written on the 10-year Treasury futures (TY), column (3) for options written on the 5-year Treasury futures (FV), and column (4) for options written on the Eurodollar (ED).

Panel A: All options

\begin{tabular}{lllll}
\hline & $(1)$ & $(2)$ & $(3)$ & $(4)$ \\
& US & TY & FV & ED \\
\hline constant & -0.67134 & -0.33427 & $-1.32860^{* *}$ & -0.06627 \\
economic $\sigma$ & $0.01064^{*}$ & 0.00382 & $0.01523^{* * *}$ & 0.01087 \\
$R^{2}$ & 0.0864 & 0.0459 & 0.2104 & 0.0184 \\
observations & 32 & 32 & 32 & 32 \\
\hline
\end{tabular}

Panel B: Call options

\begin{tabular}{lllll}
\hline & $(1)$ & $(2)$ & $(3)$ & $(4)$ \\
& US & TY & FV & ED \\
\hline constant & -1.00391 & 0.34584 & -0.30697 & -1.4007 \\
economic $\sigma$ & $0.01567^{*}$ & 0.00189 & 0.00777 & $0.03208^{*}$ \\
$R^{2}$ & 0.1042 & 0.0040 & 0.0151 & 0.0628 \\
observations & 32 & 32 & 32 & 32 \\
\hline
\end{tabular}

Panel C: Put options

\begin{tabular}{lllll}
\hline & $(1)$ & $(2)$ & $(3)$ & $(4)$ \\
& US & TY & FV & ED \\
\hline constant & -0.57489 & $-0.63916^{*}$ & $-1.15664^{* *}$ & 0.16554 \\
economic $\sigma$ & 0.01089 & $0.006766^{*}$ & $0.01270^{* *}$ & 0.00436 \\
$R^{2}$ & 0.0512 & 0.1121 & 0.1694 & 0.0062 \\
observations & 32 & 32 & 32 & 32 \\
\hline
\end{tabular}

$* * *, * *$, and $*$ denote statistical significance at the one, five, and 10 percent levels, respectively. 


\section{Table 6: Bond market options open interest}

This table shows the results of estimating the following regression:

$$
\left(\text { Oint }_{t}-\text { Oint }_{t-1}\right) / \text { Oint }_{t-1}=\alpha+\beta \sigma_{t}+e_{t},
$$

where Oint $_{t}$ is the open interest for option contracts with the closest quarterly maturity traded on the release day $t$. Column (1) shows the results for options on the 30-year Treasury futures (US), column (2) for options written on the 10-year Treasury futures (TY), column (3) for options written on the 5-year Treasury futures (FV), and column (4) for options written on the Eurodollar (ED).

Panel A: All options

\begin{tabular}{lllll}
\hline & $(1)$ & $(2)$ & $(3)$ & $(4)$ \\
& US & TY & FV & ED \\
\hline constant & 0.01913 & $0.03532^{* * *}$ & $0.05235^{* *}$ & 0.00793 \\
economic $\sigma$ & -0.00006 & $-0.00029^{* *}$ & $-0.00039^{*}$ & $-0.00009^{*}$ \\
$R^{2}$ & 0.0144 & 0.1561 & 0.0695 & 0.0834 \\
observations & 32 & 32 & 32 & 32 \\
\hline
\end{tabular}

Panel B: Call options

\begin{tabular}{lllll}
\hline & $(1)$ & $(2)$ & $(3)$ & $(4)$ \\
& US & TY & FV & ED \\
\hline constant & 0.03241 & $0.03686^{*}$ & 0.04222 & 0.00237 \\
economic $\sigma$ & -0.00014 & $-0.00036^{*}$ & -0.00018 & -0.00007 \\
$R^{2}$ & 0.0031 & 0.0949 & 0.0055 & 0.0146 \\
observations & 32 & 32 & 32 & 32 \\
\hline
\end{tabular}

Panel C: Put options

\begin{tabular}{lllll}
\hline & $(1)$ & $(2)$ & $(3)$ & $(4)$ \\
& US & TY & FV & ED \\
\hline constant & 0.01394 & 0.03670 & $0.05265^{*}$ & $0.01896^{*}$ \\
economic $\sigma$ & -0.00005 & -0.00024 & $-0.00042^{*}$ & $-0.00017^{*}$ \\
$R^{2}$ & 0.0021 & 0.0290 & 0.0699 & 0.096 \\
observations & 32 & 32 & 32 & 32 \\
& & & &
\end{tabular}

$* * *, * *$, and $*$ denote statistical significance at the one, five, and 10 percent levels, respectively. 


\section{Table 7: S\&P 500 index options volume}

This table shows the results of estimating the following regression:

$$
\left(\text { Volu }_{t}-\text { Volu }_{t-1}\right) / \text { Volu }_{t-1}=\alpha+\beta \sigma_{t}+e_{t},
$$

where Volu $_{t}$ is the trading volume for option contracts written on the S\&P 500 index on the release day $t$. Column (1) shows the results for options written on the shortest traded maturity and column (2) for the next traded maturity.

Panel A: All options

\begin{tabular}{lll}
\hline & $(1)$ & $(2)$ \\
& short maturity & medium maturity \\
\hline average time to maturity (days) & 15.26 & 45.85 \\
average no. of traded options & 47.07 & 33.59 \\
constant & -0.33601 & 0.84945 \\
economic $\sigma$ & 0.00478 & 0.00471 \\
$R^{2}$ & 0.0653 & 0.0212 \\
observations & 27 & 27 \\
\hline
\end{tabular}

Panel B: Call options

(1)

(2)

short maturity medium maturity

\begin{tabular}{llc} 
average time to maturity (days) & 15.26 & 45.85 \\
average no. of traded options & 20.63 & 14.37 \\
constant & -0.46587 & 0.79421 \\
economic $\sigma$ & 0.00608 & -0.00235 \\
$R^{2}$ & 0.0654 & 0.0017 \\
observations & 27 & 27 \\
\hline
\end{tabular}

Panel C: Put options

\begin{tabular}{lll}
\hline & $(1)$ & $(2)$ \\
& short maturity & medium maturity \\
\hline average time to maturity (days) & 15.26 & 45.85 \\
average no. of traded options & 26.44 & 19.22 \\
constant & -0.00401 & $1.30675^{*}$ \\
economic $\sigma$ & 0.00184 & 0.00722 \\
$R^{2}$ & 0.0074 & 0.0602 \\
observations & 27 & 27 \\
\hline
\end{tabular}

$* * *, * *$, and $*$ denote statistical significance at the one, five, and 10 percent levels, respectively. 


\section{Table 8: S\&P 500 index options open interest}

This table shows the results of estimating the following regression:

$$
\left(\text { Oint }_{t}-\text { Oint }_{t-1}\right) / \text { Oint }_{t-1}=\alpha+\beta \sigma_{t}+e_{t},
$$

where Oint $_{t}$ is the open interest for option contracts written on the S\&P 500 index on the release day $t$. Column (1) shows the results for options written on the shortest traded maturity and column (2) for the next traded maturity.

Panel A: All options

\begin{tabular}{lll}
\hline & $(1)$ & $(2)$ \\
& short maturity & medium maturity \\
\hline average time to maturity (days) & 15.26 & 45.85 \\
average no. of traded options & 47.07 & 33.59 \\
constant & $0.02279^{* *}$ & 0.02849 \\
economic $\sigma$ & -0.54726 & 0.00016 \\
$R^{2}$ & 0.0118 & 0.0103 \\
observations & 27 & 27 \\
\hline
\end{tabular}

Panel B: Call options

(1)

(2)

short maturity medium maturity

\begin{tabular}{llc}
\hline average time to maturity (days) & 15.26 & 45.85 \\
average no. of traded options & 20.63 & 14.37 \\
constant & 0.00993 & 0.00720 \\
economic $\sigma$ & 0.00004 & -0.00039 \\
$R^{2}$ & 0.0016 & 0.0588 \\
observations & 27 & 27 \\
\hline
\end{tabular}

Panel C: Put options

\begin{tabular}{lll}
\hline & $(1)$ & $(2)$ \\
& short maturity & medium maturity \\
\hline average time to maturity (days) & 15.26 & 45.85 \\
average no. of traded options & 26.44 & 19.22 \\
constant & $0.03521^{* *}$ & 0.02268 \\
economic $\sigma$ & -0.00019 & 0.00025 \\
$R^{2}$ & 0.0510 & 0.0202 \\
observations & 27 & 27 \\
\hline
\end{tabular}

$* * *, * *$, and $*$ denote statistical significance at the one, five, and 10 percent levels, respectively. 


\section{Table 9: Cyclical stocks options volume}

This table shows the results of estimating the following regression:

$$
\left(\text { Volu }_{t}-\text { Volu }_{t-1}\right) / \text { Volu }_{t-1}=\alpha+\beta \sigma_{t}+e_{t},
$$

where $\mathrm{Volu}_{t}$ is the trading volume for option contracts written on cyclical stocks on the release day $t$. Column (1) shows the results for options written on the shortest traded maturity and column (2) for the next traded maturity.

Panel A: All options

\begin{tabular}{lll}
\hline & $(1)$ & $(2)$ \\
& short maturity & medium maturity \\
\hline average time to maturity (days) & 15.26 & 45.85 \\
average no. of traded options & 77.07 & 111.26 \\
constant & -0.48866 & -0.58327 \\
economic $\sigma$ & $0.00706^{*}$ & $0.00816^{*}$ \\
$R^{2}$ & 0.0884 & 0.1037 \\
observations & 27 & 27 \\
\hline
\end{tabular}

Panel B: Call options

(1)

(2)

short maturity medium maturity

\begin{tabular}{lll} 
average time to maturity (days) & 15.26 & 45.85 \\
average no. of traded options & 39.37 & 60.00 \\
constant & -0.31805 & -0.69155 \\
economic $\sigma$ & 0.00523 & $0.01002^{*}$ \\
$R^{2}$ & 0.0323 & 0.1147 \\
observations & 27 & 27 \\
\hline
\end{tabular}

Panel C: Put options

\begin{tabular}{lll}
\hline & $(1)$ & $(2)$ \\
& short maturity & medium maturity \\
\hline average time to maturity (days) & 15.26 & 45.85 \\
average no. of traded options & 37.70 & 51.26 \\
constant & -0.77799 & -0.57321 \\
economic $\sigma$ & $0.01119^{* *}$ & $0.00745^{*}$ \\
$R^{2}$ & 0.1546 & 0.0949 \\
observations & 27 & 27 \\
\hline
\end{tabular}

$* * *, * *$, and $*$ denote statistical significance at the one, five, and 10 percent levels, respectively. 


\section{Table 10: Cyclical stocks options open interest}

This table shows the results of estimating the following regression:

$$
\left(\text { Oint }_{t}-\text { Oint }_{t-1}\right) / \text { Oint }_{t-1}=\alpha+\beta \sigma_{t}+e_{t},
$$

where Oint $_{t}$ is the open interest for option contracts written on cyclical stocks on the release day $t$. Column (1) shows the results for options written on the shortest traded maturity and column (2) for the next traded maturity.

Panel A: All options

\begin{tabular}{lll}
\hline & $(1)$ & $(2)$ \\
& short maturity & medium maturity \\
\hline average time to maturity (days) & 15.26 & 45.85 \\
average no. of traded options & 77.07 & 111.26 \\
constant & $0.03570^{* *}$ & $0.12979^{* * *}$ \\
economic $\sigma$ & -0.00012 & $-0.00085^{* *}$ \\
$R^{2}$ & 0.0271 & 0.1745 \\
observations & 27 & 27 \\
\hline
\end{tabular}

Panel B: Call options

(1)

short maturity medium maturity

\begin{tabular}{lll}
\hline average time to maturity (days) & 15.26 & 45.85 \\
average no. of traded options & 39.37 & 60.00 \\
constant & 0.00933 & $0.12800^{* * *}$ \\
economic $\sigma$ & -0.00015 & $-0.00083^{* *}$ \\
$R^{2}$ & 0.0210 & 0.1823 \\
observations & 27 & 27
\end{tabular}

Panel C: Put options

\begin{tabular}{lll}
\hline & $(1)$ & $(2)$ \\
& short maturity & medium maturity \\
\hline average time to maturity (days) & 15.26 & 45.85 \\
average no. of traded options & 37.70 & 51.26 \\
constant & $0.08012^{* * *}$ & $0.12488^{* * *}$ \\
economic $\sigma$ & $-0.00052^{*}$ & $-0.00077^{*}$ \\
$R^{2}$ & 0.1121 & 0.1242 \\
observations & 27 & 27
\end{tabular}

$* * *, * *$, and $*$ denote statistical significance at the one, five, and 10 percent levels, respectively. 


\section{Figure 1: Data}

This figure shows an example of the data source used to obtain economic derivatives prices. Goldman Sachs compiles a report at the end of each auction on U.S. Non-Farm Payrolls containing the final prices of vanilla and digital call and put options, for each level of strike prices. The clearing prices are the final outcome of the auction. In contrast, the ask and bid prices are automatically generated by adding and subtracting a fixed fee from the clearing prices.

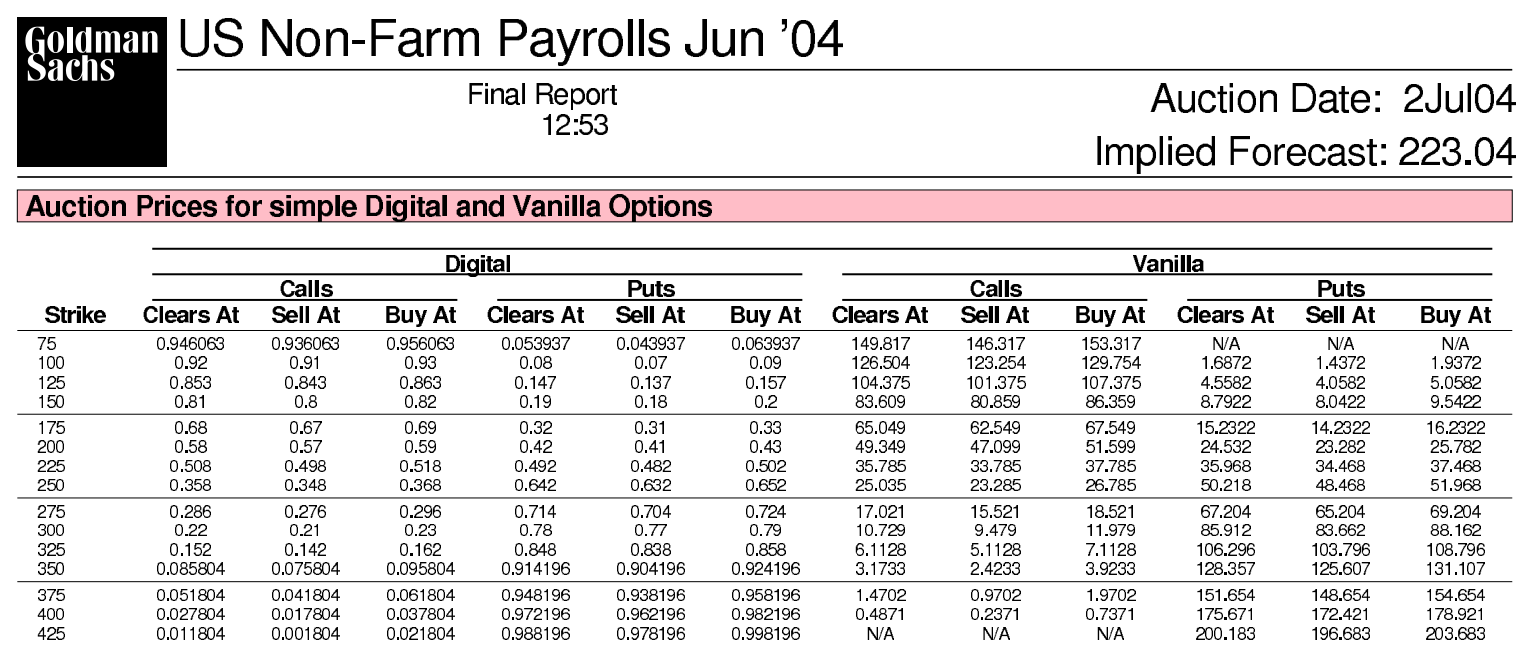


Figure 2: Macroeconomic uncertainty and financial markets volatility

This plot shows a time-series of the macroeconomic uncertainty implicit in the price of economic derivatives (dotted line), the VIX (light continuous line), and the implied volatility of options written on the 30-year Treasury bond futures (dark continuous line).

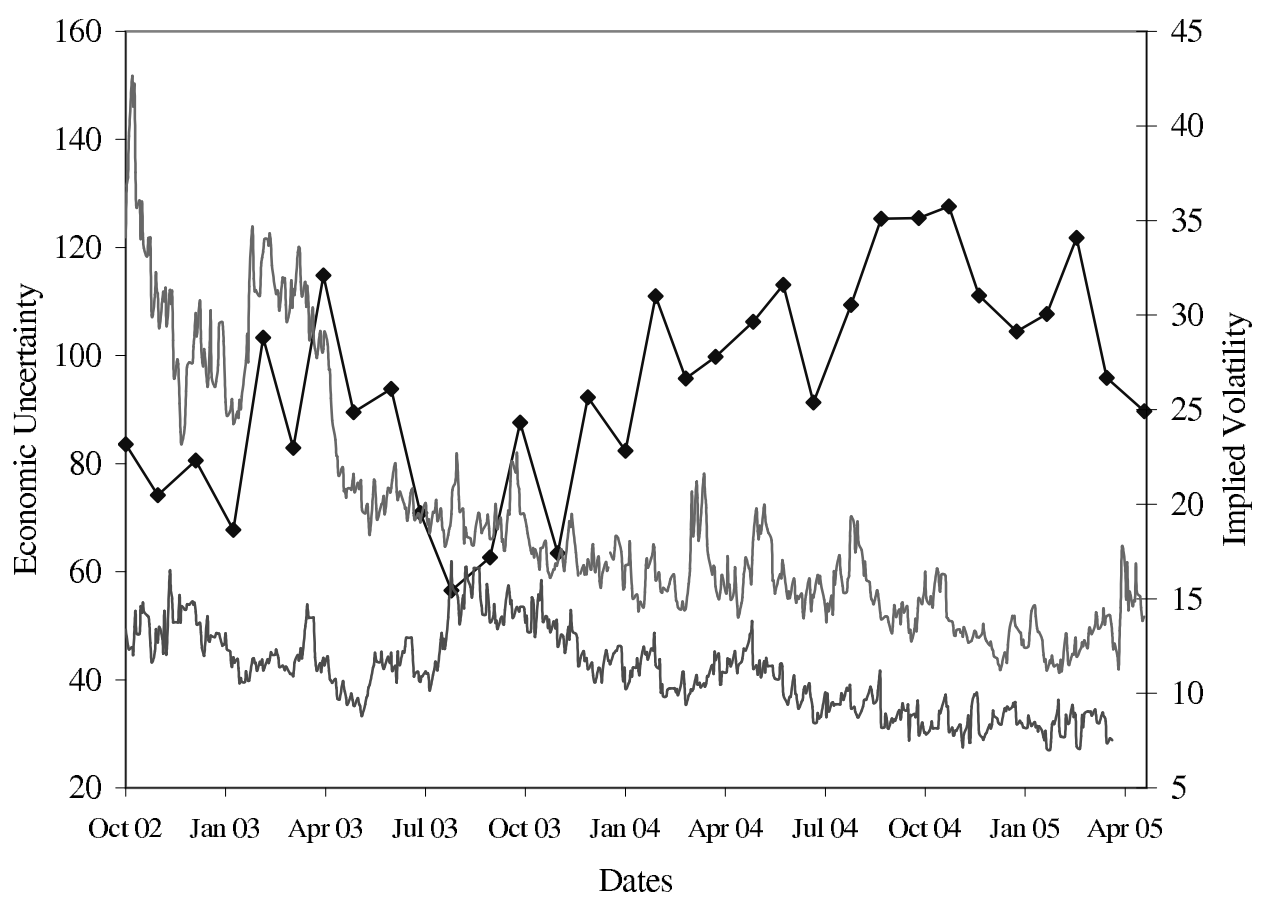

